\title{
LIPIODOL IN THE DIAGNOSIS OF CONGENITAL OESOPHAGEAL ATRESIA
}

BY

C. FRASER BROCKINGTON, M.D., D.P.H.,

Late Assistant County Medical Officer, Worcestershire, AND

REGINALD LIGHTWOOD, M.D., M.R.C.P., D.P.H., Assistant Physician for Diseases of Children, Westminster Hospital.

(From the Hospital for Sick Children, Great Ormond Street, London.)

Two infants, aged 12 and 6 days at the time of death, were admitted to the Hospital for Sick Children, Great Ormond Street, with the history of 'going blue and suffocating' on attempting to take food. The injection of

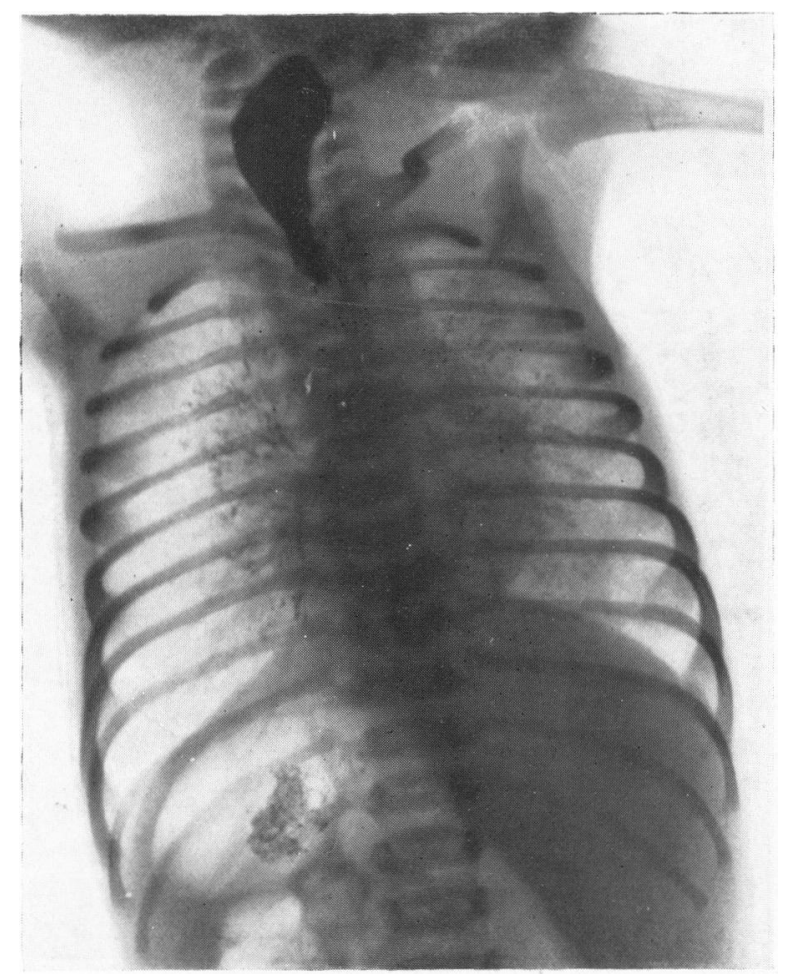

FIG. 1. Case 1.-The shadow of the blind œesophagus is seen above the level of the clavicles. Lipiodol, spilt back into the larynx, has passed down the trachea, has outlined the bronchial tree, and has also reached the stomach by way of a trachenbronchial fistula. 
5 c.cm. of lipiodol into the œesophagus during life was successful in establishing by radiography the diagnosis of atresia of the osophagus in both cases. In practice this may be performed with the aid of fluoroscopy. The accompanying radiograms demonstrate the conditions found on admission to hospital.
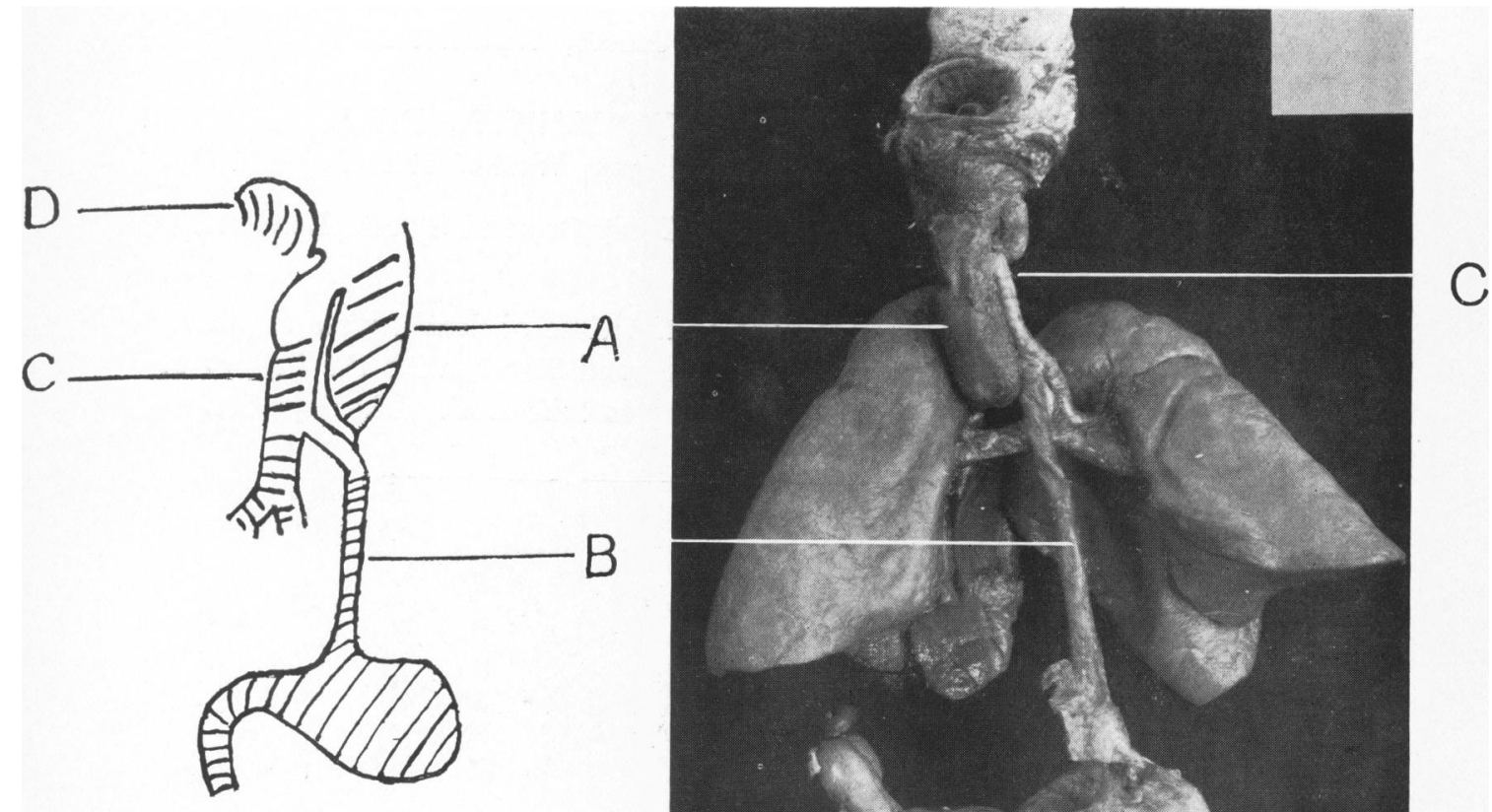

A Blind œsophagus.

B Lower œsophagus, patent.

C Trachea.

D Tongue

FIG. 2. Case 1.-Above, the blind osophagus is seen. Below, the osophagus leads out of the trachea just above its bifurcation.

In Case 1 (investigated June, 1932), skiagrams during life showed a blind end to the œsophagus with a little lipiodol both in the stomach and in the lungs (Fig. 1). A post-mortem examination in this infant revealed complete atresia of the oesophagus with a communication extending from the bifurcation of the trachea to the lower portion of the œsophagus (Fig. 2).

It was thus evident that the lipiodol present in the lungs and stomach of this infant in the ante-mortem skiagrams had spilt over from the upper end of the osophagus into the trachea, thus finding its way into the bronchial tree and, through the fistula, into the stomach, 
In Case 2 (investigated October, 1932), the ante-mortem radiograms suggested complete atresia of the œesophagus (Fig. 3). It was not possible to obtain a post-mortem examination in this case, but post-mortem radiography after the injection of lipiodol into the trachea, and into the œsophagus from above and below, was sufficient to show the existence of complete atresia without tracheo-œsophageal fistula (Fig. 4).

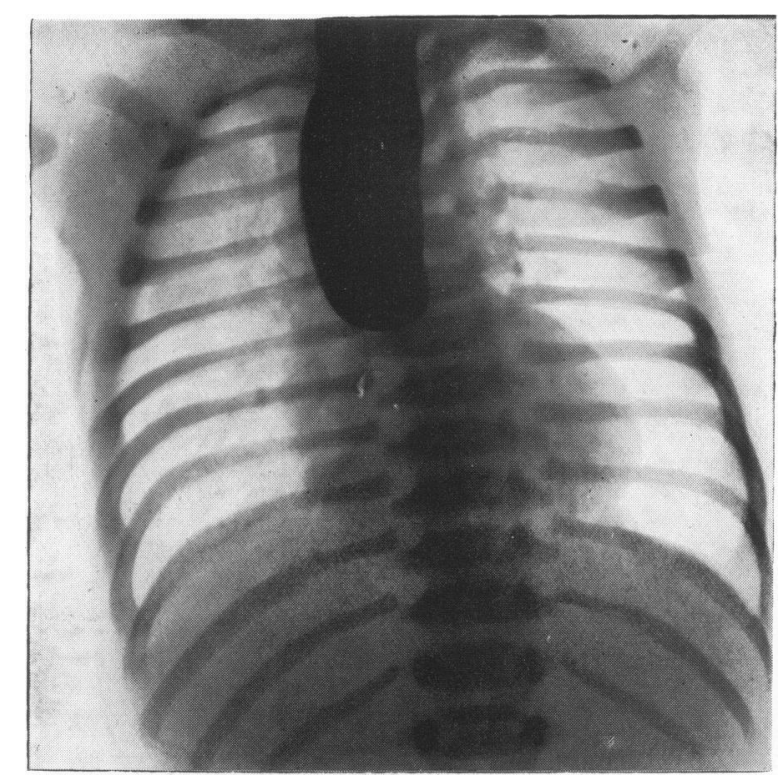

Fig. 3. Case 2.-Ante-mortem radiography. The osophagus which is dilated, ends blindly at the level of the sixth costal cartilage.

\section{Discussion.}

This aid to the diagnosis of congenital œsophageal atresia, also reported upon by Reid ${ }^{1}$ soon after the beginning of our work, is of more than academic interest. The clinician, confronted with a new-born infant presenting the symptoms of choking and cyanosis on feeding, may be required to give a definite diagnosis of congenital atresia, a diagnosis which carries with it an invariably fatal prognosis. Radiological confirmation of his diagnosis may be valuable. The expectation of life of the 250 or more cases ${ }^{2}$ which have been reported since the condition was originally described by Durston ${ }^{8}$ in 1670 does not, in the absence of surgical intervention so far considered inadvisable ${ }^{6}$, exceed 13 days. It is of interest that the two infants reported here present examples of both types of congenital atresia known to occur ${ }^{3}$, . The first case is an example of the commoner variety, namely, atresia with tracheo-œsophageal fistula. This occurs in 84 to 92 per cent. of recorded 
instances", 1, and only about 10 per cent (of which the second case is an example) consist of simple atresia without fistula. For a discussion of the probable mechanism producing atresia of the œesophagus in the newborn, reference may be made to the writings of Keith and Spicer ${ }^{3}$ and of Sheldon ${ }^{5}$.

We are indebted to Dr. Poynton for permission to publish these two cases, and to Dr. Shires for help in the interpretation of the radiograms.

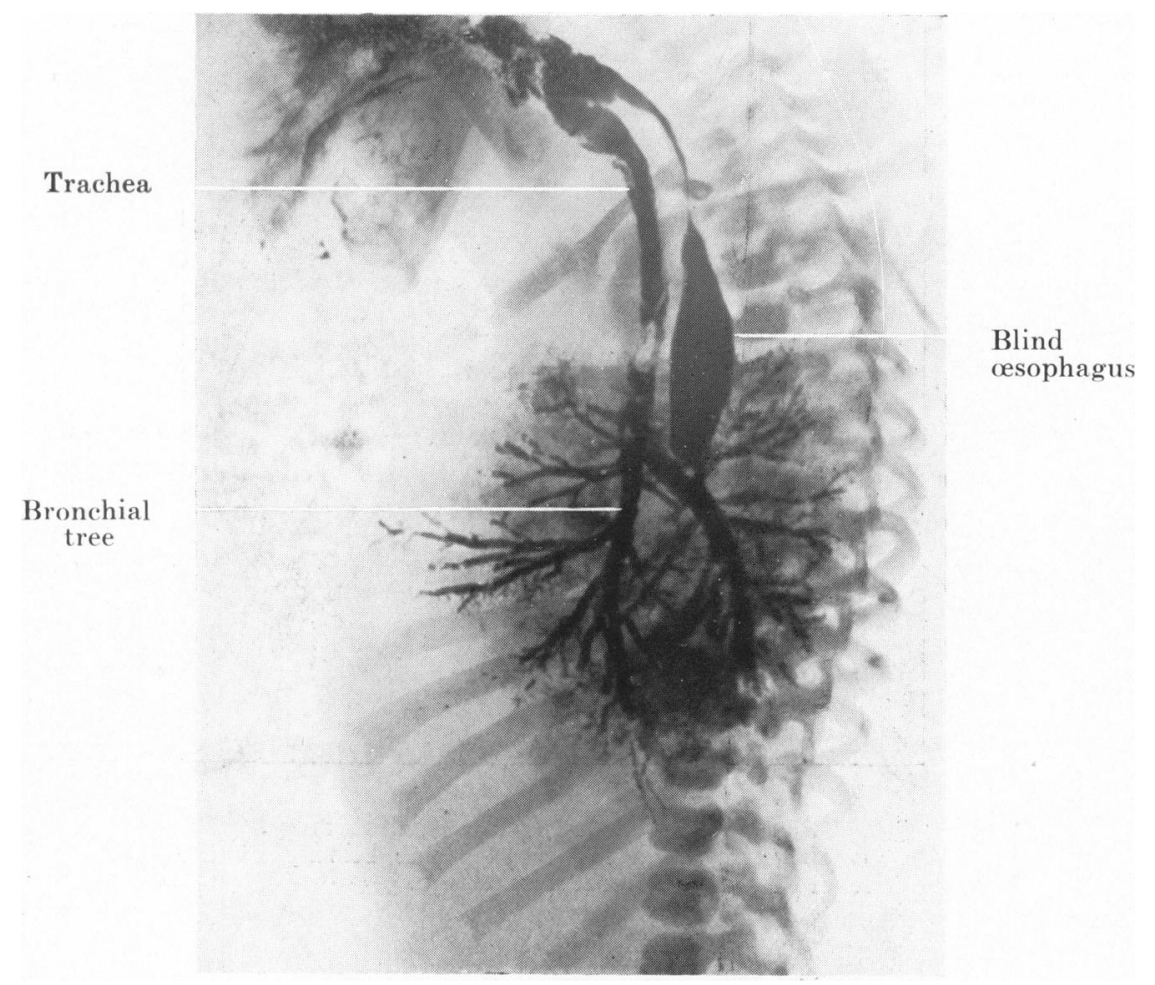

FI(. 4. Case 2.-Post-mortem radiography. First the blind oesophagus was filled with sodium iodide. Subsequently the bronchial tree was injected. If a tracheo-œsophageal fistula had been present some of the opaque fluid would have passed into the stomach.

1. Reid, M. D., J. Pediat., St. Louis, 1932, I, 87.

2. Rosenthal, A., \& Himmelstein, U., Arch. Ped., N.Y., 1932, XLIX, 444.

3. Keith, A., \& Spicer, J. Anat. \& Phys., Lond., 1907, XLI, 52.

4. Heumann, J., Abt's Pediatrics, Philad., 1st Edition, 1924, III, 406.

5. Sheldon, W. P. H., Arch. Dis. Childh., Lond., 1926, I, 279.

6. von Reuss, A. R., Dis. of Nerwborn, Lond., 1921, 251.

7. Cautley, E., Brit. J. Dis. Child., Lond., 1917, XIV, 1.

8. Durston, Collect. Academ, Part. etrang, 1670, t. ii, 288 , 